\title{
Undergraduate medical student education: the case for a national curriculum
}

\author{
M. F. GIBSON \& M. J. CLANCY \\ Accident and Emergency Department, Leeds General Infirmary, Leeds
}

\section{SUMMARY}

Thirty-eight teaching hospital affiliated accident and emergency departments were surveyed by post to try to find if there had been any change in undergraduate medical student teaching over the past 10 years. Twenty-six departments replied. The results showed that although there has been an improvement in the teaching of A\&E medicine to undergraduates in the past few years there are still some medical schools where an $A \& E$ attachment is not mandatory. In those departments providing teaching, there is wide variation in course duration and content.

\section{INTRODUCTION}

With the development of A\&E as a specialty in its own right and expansion of consultant numbers we decided to update our knowledge of undergraduate teaching in the specialty - a subject not reviewed since 1980 when Wakeford \& Yates published a survey which highlighted considerable differences in the arrangements made in the various medical schools.

In order to get a broadly similar spectrum of information a questionnaire was circulated to teaching hospital affiliated departments. These departments were identified using a list of medical schools and the C.S.A. handbook.

Of the 38 teaching hospital A\&E departments surveyed, 26 of them returned a completed questionnaire after two mail shots; this amounts to $68 \%$.

\section{METHOD}

The questionnaire was sent to the consultant-in-charge of the departments. They were asked if their medical school timetabled specific A\&E teaching attachments for all medical students, the duration of the attachments, the group size, teaching

Correspondence: Mr M. F. Gibson, Accident and Emergency Department, Leeds General Infirmary, Great George Street, Leeds, U.K. 
methods, and if A\&E teaching had significantly altered in the last 5 years in their hospital. They were also asked what changes they would like to make to their present teaching arrangements.

A separate section assessed the teaching of cardiopulmonary resuscitation.

\section{RESULTS}

The percentages indicated relate to the number of replies recieved i.e. a percentage out of 26 .

\section{Attachments}

Fifty-two per cent said that their medical school timetable an attachment to an A\&E department in a teaching hospital for all students, and $28 \%$ said that they used peripheral hospitals to provide the main A\&E attachment for some students. Twenty per cent, or five departments, said that their medical school didn't provide an attachment to a teaching hospital department for all medical students - nor were peripheral hospitals used to provide the main A\&E attachments for their students. This would seem to indicate that either no formal attachment was made at all - which was indeed the case in three departments - but the two other replies went on to indicate that some students did indeed have attachments, and some teaching was given, but not to all medical students.

Group size

Figure 1 shows the distribution of group sizes if it was specified in the reply. The range was two to fourteen students.

\section{Duration of attachment}

The replies to this section were more difficult to assess, as the durations of attachment were very variable with in many cases only a proportion of the time being spent in A\&E. The shortest attachment was 4 days, and the longest attachment, although it was part-time was 8 weeks.

\section{Methods of instruction}

Figure 2 shows the various methods of instruction used in teaching the medical students.

It is likely that the small size of some of the student groups, making them unsuitable for formal lectures accounts for the greater popularity of tutorials and bedside teaching. Only one department regularly used cadavers as a teaching aid.

In retrospect this question should have been asked in a more specific way, as many departments probably allow students to practice intubation on patients who have failed to survive attempted resuscitation. 


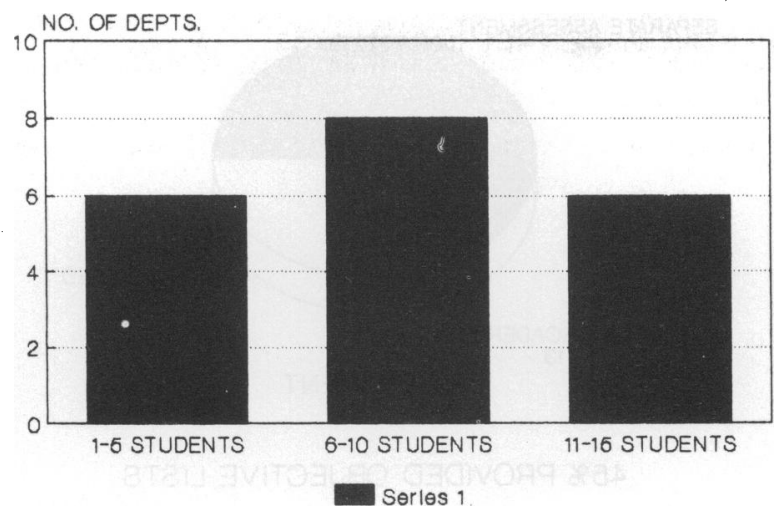

Fig. 1. Group size (if specified).

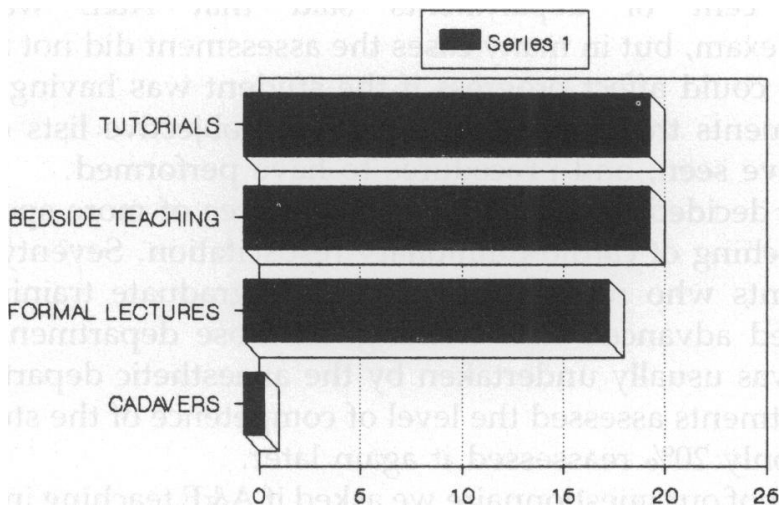

Fig. 2. Methods of instruction.

We tried to make more sense of the duration of attachment figures by asking the number of hours of $A \& E$ lectures given. The range was from $0-40 \mathrm{~h}$ and the mean was $6.7 \mathrm{hrs}$.

Six departments provided 10 or more hours of lectures, and of these three departments provided in excess of $20 \mathrm{~h}$.

\section{Assessment}

Figure 3 shows how A\&E teaching is assessed. Obviously, those departments not undertaking formal training in $A \& E$ do not assess it, and one of the other teaching departments was not undertaking any assessment.

Sixty-five per cent of respondents said that A\&E teaching was assessed as a separate subject, $60 \%$ of these by some sort of written exam, and $40 \%$ informally by attendance, case presentations, or purely on the impression of the clinical teacher. 


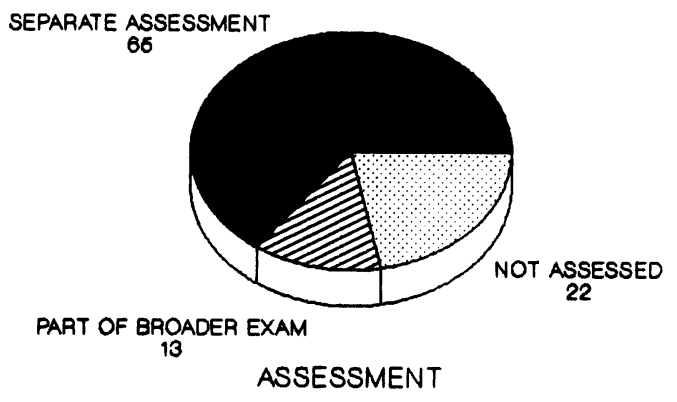

45\% PROVIDED OBJECTIVE LISTS

Fig. 3. Assessment of accident and emergency.

Thirteen per cent of departments said that A\&E was assessed asiv part of a broader exam, but in many cases the assessment did not form part of finab exam marks, but could affect progress if the student was having problems.

Of the departments that replied $45 \%$ provided objective lists of conditions, of procedures to have seen, and procedures to have performed.

In addition we decided to undertake a smaller area of more specific questioning related to the teaching of cardio-pulmonary resuscitation. Seventy-two per cent o the 26 departments who replied provided undergraduate training in basic CBR and $68 \%$ provided advanced CPR training. In those departments not providi CPR training it was usually undertaken by the anaesthetic department. Sixty-fợio per cent of departments assessed the level of competence of the student at the times of training, but only $20 \%$ reassessed it again later.

As the final part of our questionnaire we asked if A\&E teaching in that departmen had undergone any changes in the last 5 years, and also what improvements the respondent would like to see in the teaching in their departments. All departments? except seven said improvements had occurred. Of those seven, one department had suffered a reduction in teaching time, and in the remaining six no improvementso had occurred.

Five departments had had introduction of a formal teaching programme for undergraduates and these seemed to coincide with departments where there had been a first consultant appointment in the last 5 years.

In response to the question concerning what improvements consultants woulde like to see, we received a wide range of responses, which could readily bef summarized as follows:

(1) Better facilities for teaching;

(2) More staff, particularly experienced middle grade staff or more consultants and

(3) More input to the central lecture programme.

Clearly, judging from some of the replies, there could be no improvement untip more facilities or staff were made available, as several departments had only one consultant and no middle grade staff. 
Overall there appears to have been an improvement in A\&E teaching brought about by more organization of teaching with formal lectures and tutorials and more widespread assessment of students. Partly this has been brought about by the expansion of the consultant grade, but there are still medical schools where there is no formal attachment to an A\&E department provided for all students. However, even at these medical schools, students are expected to gain experience in A\&E medicine on other firms - for instance when the surgical team to which they are attached is 'on take'.

\section{DISCUSSION}

As can be seen there is still an enormous diversity of approach and content in this vital area of medical strudent education.

Tachakra, in Archives of Emergency Medicine (June, 1988) suggested the formation of an organization of Teachers of Emergency Medicine along the lines of the Society of Teachers of Emergency Medicine in the United States.

We would propose that the teaching of undergraduates should be considered in three distinct phases. Immediate care, or first aid, needs to be taught to the student as soon as possible on arrival at medical school, and there is evidence from this survey that this is being more widely undertaken. Formal lectures need to be incorporated into the teaching arranged for students in their first clinical year. Department staff are the best equipped to deal with specific A\&E subject matter. A period of attachment to a department should be regarded as indispensable and is probably best incorporated into the second clinical year when the student has acquired basic clinical skills.

Finally, we have shown that there is a wide variation in the teaching and assessment of $A \& E$ ranging from none to a full course. A\&E as a specialty is expanding and is recognized as being increasingly relevant in the training of doctors. Doctors themselves appreciate this as shown by a survey where postgraduate doctors ranked A\&E in the top five specialties (Wright, 1979).

The goals of A\&E teaching need to be better defined so that the other specialties know where they stand and avoid teaching overlap. If this is done there will be more uniformity of teaching leading to better preparation for medical practice in general, and A\&E in particular.

\section{REFERENCES}

Tachakra S. (1988) Editorial: Teaching medical students. Archives of Emergency Medicine 5, 55-8.

Wakeford R., \& Yates D. (1980) Accident and Emergency teaching in U.K. medical schools. Medical Teacher 2, 93-5.

Wright V., Hopkins R., \& Burton K. E. (1979) What shall we teach undergraduates? British Medical Journal 1, 805-7. 